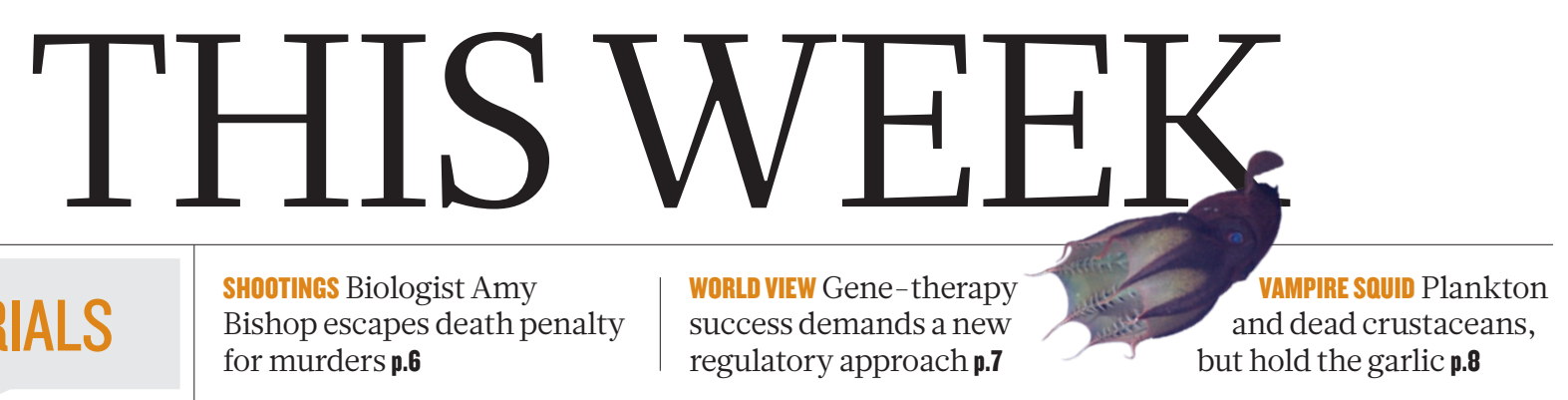

\section{EDITORIALS}

WORLD VIE G regulatory approach $\mathbf{p . 7}$

\title{
The price of progress
}

\section{A new uranium enrichment technique approved by the US Nuclear Regulatory Commission could have an impact on nuclear proliferation. This should have been taken into account.}

S cientists and scientific journals are naturally inclined towards progress. But there are exceptions: progress is not always better. Last week, the US Nuclear Regulatory Commission (NRC) in Rockville, Maryland, announced that it had issued a licence for a new technology to enrich uranium using lasers - a process that is potentially cheaper and better than current enrichment methods, but also politically fraught and possibly dangerous (see Nature http://doi.org/ jfr; 2012). The decision was unfortunate. The NRC should introduce rules to ensure that its future moves are better informed.

Nuclear power and nuclear weapons both require uranium that has been enriched to contain higher levels of uranium-235 than occurs naturally. The 1970 nuclear non-proliferation treaty gives countries the right to possess enrichment systems, but most are subject to strict controls. Where facilities are declared as peaceful, they are subject to inspection by the International Atomic Energy Agency, which ensures that material is not diverted for military or criminal purposes. National intelligence agencies, too, keep a careful eye on the activities of friends and rivals worldwide.

Current techniques to separate uranium-235 from its heavier, nonfissile sibling uranium-238 are hard to hide. They typically involve enormous gaseous-diffusion plants, or smaller, energy-intensive centrifuge facilities that spin the two isotopes apart in high-speed machines. Both require lots of space and electricity, which means that such facilities are easy to spot with, say, satellite reconnaissance.

Lasers are more discreet. When finely tuned, they can ionize uranium-235 that can then be collected on a negatively charged plate. The new technique will require considerably less space and electricity than centrifuge or diffusion plants.

GE Hitachi, the multinational company pursuing laser enrichment, describes it as a "game-changing technology", and those who fear nuclear proliferation agree. Understanding where enrichment facilities are and how they operate is crucial to maintaining the treaties and agreements that limit the spread of nuclear technology. When undeclared enrichment facilities are uncovered, as happened in Iran in 2009, it can spark an international crisis. Even more worrying is the possibility that some facilities can simply never be detected. Mistrust could lead to regional arms races and even open conflicts.

When the NRC approved GE Hitachi's application for a laser enrichment plant, it considered physical security, such as the height of the fence around the plant. But the commission did not explicitly address the existential threat that a plant might pose to the non-proliferation regime, nor did it concern itself with the message that the pursuit of this technology might send to other nuclear nations.

The American Physical Society (APS), based in College Park, Maryland, would like to change that. Backed by environment groups and scientists, the society has proposed that the NRC change its regulations to require future applicants to submit a 'proliferation review'. This would force the commission and corporations to consider the

proliferation consequences of their proposed facilities. It would also provide a public focus for debate, much as environmental-impact statements have allowed activists and citizens to query the environmental aspects of construction.

Could such a review have changed the outcome of the NRC's licence decision? Perhaps. From a commercial standpoint, the benefit of laser enrichment is clear, but from a broader societal perspective, it is questionable. The cost of fuel for nuclear reactors is dwarfed by the cost

"To consider proliferation might seem beyond the remit of a regulator, but it is not." of construction, and this has stalled a nuclear renaissance in the West. A 2010 analysis showed that the savings to households would be less than US\$10 per year from laser enrichment - a saving that many homeowners might be unwilling to accept if presented with the risks the technology poses (see F. Slakey and L. R. Cohen Nature 464, 32-33; 2010).

The APS's proposed rule change will be voted on by the five NRC commissioners in November. Nature urges the commissioners (who were not directly involved in approving the laser enrichment system) to approve the change. To consider something as vague as proliferation might seem beyond the remit of a regulator, but it is not. Under the Atomic Energy Act of 1954, the NRC is charged with considering whether its licences would "be inimical to the common defense and security" of the US public. Nuclear technologies that are potentially destabilizing pose a threat to the security of citizens everywhere, and so the commission could rightly consider it under an altered licensing process. In the case of laser enrichment, as with other technologies, progress should be judged on more than the technical merits alone.

\section{Power cuts}

\section{China's slumping renewable-energy industry should be learnt from, not dismissed.}

$\mathrm{T}$ hese are testing times for the renewable-energy boom in China. On 3 August, the head of a Chinese solar-energy company leapt to his death because his firm couldn't pay off a loan. Last month, LDK Solar in Xinyu City cut its earnings forecast for the second consecutive time, and watched its stock drop to one-quarter of what it was a year ago after it defaulted on payments. Suntech Power in Wuxi, the world's biggest producer of solar panels, announced plans to slash production and was forced to accept a loan worth US $\$ 32$ million from the local government to stay afloat. China's wind-turbine manufacturers are also being forced to watch sales drop in an overcapacity market. 
China - which produces more solar panels and wind turbines than any other country - likes to promote its renewable-energy industry as a glowing symbol of a technology-driven, green future. But, over the past few years, a glut in the international market, a drop in prices and import tariffs introduced by countries including the United States have left companies with over-supply and debt.

Observers have jumped on the downturn with criticisms of how the Chinese government has supported and protected renewable-energy companies. A widely quoted piece in the Shanghai-based newspaper First Financial Daily claimed that the slump signalled the "imminent collapse" of the country's photovoltaics industry. A gloating editorial in The Wall Street Journal in August used events in China to warn the US government against support for its own renewables industry.

Strong stuff, but perhaps not unexpected. It is clear that some companies overshot the market, and there are some grounds for claims that China has engaged in unfair trade practices. When the country entered renewable energy, it instituted protective measures such as requiring that $70 \%$ of turbines sold in China be produced with domestically made parts, but those measures have been removed. Many renewables firms have failed and can no longer be propped up by supportive local governments.

However, it is foolish to decide that China's renewables industry has been - or will be - a failure on the basis of its current problems. The scale of some of these problems has been overstated. The Wall Street Journal, for instance, blamed decreased revenue at power companies on underperformance at wind farms, when in fact it had more to do with the increasing price of coal.

By whatever means it has been achieved — and whatever else might be said about it - China's investment in renewables has been a remarkable project. Just seven years after a renewable-energy law threw government support behind the industry, China went from having almost no stake in the international market to leading the manufacture of solar photovoltaics and wind turbines, in very competitive industries. China has developed know-how and manufacturing bases: it has the engineers, and it is ready to lead the industry into the future.

The country's targets will carry the industry forward. Some 62 gigawatts of wind power are currently installed - more than in any other country - and the government has set a target of 200 gigawatts by

"It is foolish
to decide
that China's
renewables
industry has
been a failure."
2020. An even bigger difference will come when the domestic demand for solar energy picks up, which it surely will. Until now, nearly all of China's photovoltaic units have been exported; domestic use has increased but remains at a relatively low 3.1 gigawatts.

The Chinese government is establishing policies that will encourage this. A new renewable-portfolio standard, to be implemented by the end of this year, will force power companies to generate a mandatory proportion of their energy from renewables, with penalties for those that do not. An upgrade of long-distance power lines, to transfer energy from wind farms or megasolar plants in the west of China to the energy-hungry east, was approved last year. Consumers will be forced to share the burden when a surcharge on electricity from renewables kicks in.

Chinese renewable energy has certainly hit a low point. Many of the 80 or so companies that produce wind turbines will probably have to close. But what The Wall Street Journal called a waste of time and money can be seen as healthy competition in an immature market. As China's renewables industry reorganizes and restructures itself, there may be reasons not to emulate it. But the government, for reasons relating to pollution, climate change and energy security, is firmly behind the industry. And it has built itself a solid platform from which to push on.

\section{Life sciences}

\section{Survivors of the 2010 University of Alabama shooting chose not to push for the death penalty.}

A my Bishop, the biologist who murdered three colleagues in cold blood and grievously wounded two others, will spend the rest of her life behind bars after an Alabama court sentenced her last week. The Harvard-trained assistant professor had been denied tenure at the University of Alabama in Huntsville. In February 2010, months after her appeal against the decision failed, Bishop, a mother of four, pulled out a 9-millimetre pistol during a faculty meeting in a tiny conference room.

Without saying a word, Bishop methodically shot down fellow biologists Maria Ragland Davis, Adriel Johnson and department chairman Gopi Podilla. A bullet to the head of colleague Joseph Leahy left him, after many months of recovery, blind in his right eye and partially sighted in his left. Staff assistant Stephanie Monticciolo, the department's mother hen, had the teeth on one side of her mouth knocked out. She sustained shattered sinuses and a broken jaw, and was blinded in one eye.

"Many, many things are better than I could have ever hoped," Monticciolo's adult daughter Michele posted on a blog 18 months later. "Some things, however, will never be the same."

The same is true in the biology department at Huntsville, two and a half years after the shooting. Yet signs of a determined recovery abound. Ten new graduate students enrolled in August. The department has made university biochemist Debra Moriarity its chairwoman, and has hired two new faculty members. Leahy, a microbiologist, is back teaching full-time as of this term. And last week,

structural biologists on the faculty hosted an international conference on the crystallization of biological macromolecules, attended by more than 200 scientists.

In the state of Alabama, there are only two possible sentences for capital murder, with which Bishop, now 47, was charged: life in prison with no possibility of parole, or death by lethal injection or electrocution. Prosecutors said almost from the outset that they would seek the death penalty.

At first, Bishop pleaded not guilty "by reason of mental disease or defect". Then, weeks before the trial was set to open last month, a heartening tale of human generosity began to unfold. It emerged that the spouse of one of the murdered biologists had written to judge Alan Mann, who would have the final say over the sentence if Bishop was found guilty. The letter-writer noted that his or her family had suffered greatly, but added that they could see no benefit in the loss of another life. The writer asked Mann to spare Bishop the death penalty.

The letter prompted Bishop to offer, through her lawyers, to change her plea to guilty if the prosecutors would drop their pursuit of the death penalty. The prosecutors sounded out the other survivors: the nine who had been in the conference room at the time of the shooting, and the families of the dead. None wanted the death penalty. A deal was reached and Bishop changed her plea to guilty.

Robert Broussard, the lead prosecutor on the case, told Nature this week that the common sentiment among the survivors "absolutely" swayed him not to seek the ultimate punishment. And so, on 24 September, after a brief trial, Bishop was sentenced to life behind bars.

In 25 years of prosecuting murders, Broussard said, he has never seen such equanimity in so many people affected by a violent crime. Those who will

SNATURE.COM To comment online, click on Editorials at: go.nature.com/xhunqv spend a lifetime bearing the wounds that Amy Bishop inflicted, inside and out, reached deep and found mercy. 